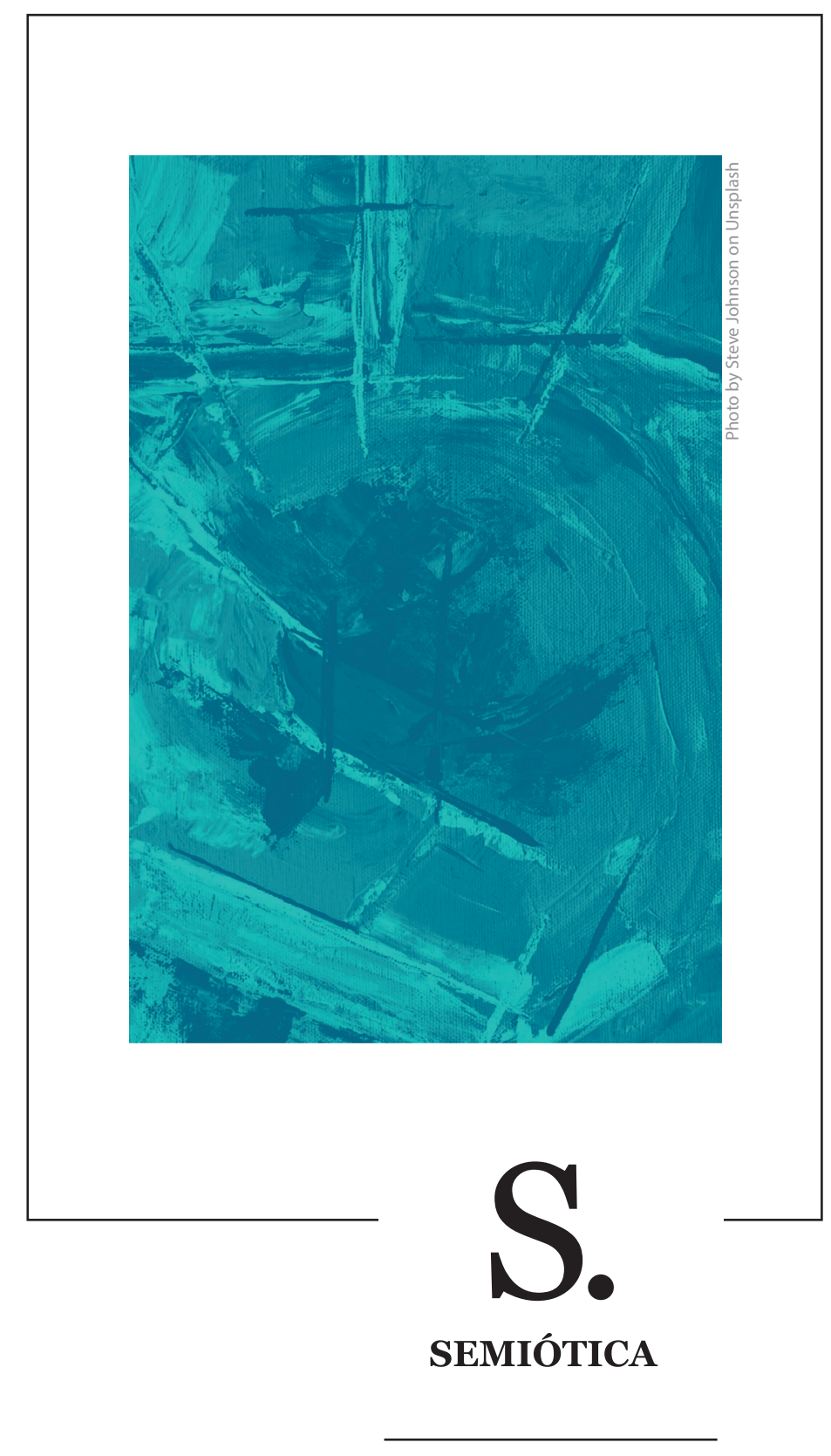




\section{Religiones asiáticas y géneros cinematográficos en las películas El Topo y La montaña sagrada de Alejandro Jodorowsky}

José Carlos Cabrejo

En la obra cinematográfica de Alejandro Jodorowsky, hallamos dos títulos destacados por su trascendencia cultural en el circuito norteamericano de películas de medianoche de los años setenta: El Topo (1970) y La montaña sagrada (The Holy Mountain, 1973). Entre otros rasgos, hay algo que las conecta íntimamente: su juego con las estructuras de género cinematográfico. Mientras que El Topo emplea las convenciones del wéstern, La montaña sagrada hace lo mismo con las de la ciencia ficción, al menos en ciertos pasajes del filme con temática tecnológica y futurista.

En cuanto a El Topo, hay que señalar que es una película que ha experimentado numerosas calificaciones por su uso de las convenciones del wéstern. Massimo Monteleone (1993) la califica como un wéstern metafísico: “En este wéstern metafísico se nace asesino cazarrecompensas y se muere monje monacal, se vive violentamente vestido de negro y se resucita 'de blanco', con una misión pacífica por cumplir" (p. 27) ${ }^{1}$. Por su parte, Diego Moldes (2012) considera al filme como un antiwéstern o contrawéstern mexicano, al deconstruir convenciones del género. Asimismo, refiere otras calificaciones de autores que nombran a la cinta como wéstern budista o zen:

El objetivo de Alejandro Jodorowsky, además de hacer una película iniciática, era el de desmontar un poco más la épica del wéstern americano creando un antiwéstern o contrawéstern mexicano como El Topo. La película sería lo nunca visto, un cruce de mitología wéstern tamizada por el budismo zen que muchos han calificado de wéstern budista (Augusto M. Torres), wéstern iniciático o, más concretamente, de wéstern zen. (p. 198)

Es importante señalar que el antiwéstern se entiende como una expresión revisionista, que supone, por lo tanto, una ruptura con el wéstern tradicional (Hall, 2001, p. 3), sea con su ideología o con su narrativa clásica. Desde los años sesenta, podemos encontrar casos de wésterns revisionistas con una mayor nitidez. Uno es La pandilla salvaje (The Wild Bunch, 1969) de Sam Peckinpah, con sus personajes centrales que viven al margen de la ley y su violencia explícita. Otro es Pequeño gran hombre (Little Big Man, 1970) de Arthur

$1 \quad$ El texto original dice así: “In questo western metafisico si nasce 'bounty-killer' e si moure monaci bonzi, si vive violentamente vestiti di nero e si resuscita 'imbiancanti', con una missione pacifica da compiere". 
Penn, con su protagonista dubitativo, su final abierto y su retrato, por un lado, cruel del Ejército de los Estados Unidos de América y, por otro, casi idealizado de los nativos cheyenes. Esta cinta rompe con la figura del héroe temerario y de valores incólumes, con el maniqueísmo de vaqueros buenos e indios malos, con la dicotomía del "salvajismo y la civilización" que refiere Roy Harvey Pearce (citado por Hall, 2001, p. 9), y con los típicos modos narrativos y de representación visual del género desde sus inicios.

Uno de los grandes teóricos interesados en la exploración del wéstern fue André Bazin. Para él, es inútil reducir la esencia de este género a sus componentes, sean las cabalgadas, los duelos o la visión de sus hombres fuertes e intrépidos, rodeados de un paisaje austero e indómito:

Nos esforzamos en vano en reducir el wéstern a uno cualquiera de sus componentes manifiestos. Los mismos elementos pueden encontrarse en otra parte, pero nunca los privilegios a los que parece que estén ligados. Es necesario que el wéstern sea otra cosa que su forma. Los atributos formales que se reconocen ordinariamente en un wéstern no son otra cosa que los signos o los símbolos de su realidad profunda, que es el mito. (Citado por Casas, 1994, p. 12)

Para Bazin, esa mitología se encuentra en una serie de expresiones literarias o folclóricas de las que se alimenta el género. Cuenta Casas (1994) que cuando apareció la película que es para muchos el primer wéstern de la historia, Asalto y robo de un tren (The Great Train Robbery, 1903), aún vivían los futuros mitos del género de los que se apoderaban los relatos orales: Buffalo Bill, Wyatt Earp, Butch Cassidy, Sundance Kid, etcétera (p. 15).

Por otro lado, el wéstern, según Vincent Pinel en su libro Los géneros cinematográficos (2009), cuenta:

en clave heroica o crítica, la conquista del Oeste de los Estados Unidos y la difícil gestación de la nación americana.

Las ficciones del wéstern se inscriben en un pasado legendario que podemos, sin embargo, situar en el tiempo (generalmente entre 1840 y 1890), fechas que a veces se transgreden, y ubicarlo al oeste del Misisipi, en ese espacio movedizo de la "Frontera" en constante progresión hacia el Pacífico.

Aunque a menudo recurre a la Historia, el wéstern solo se enmarca de forma excepcional en la película histórica. Ofrece una representación mítica de los acontecimientos, que varía sensiblemente en función del contexto de la época que este escenifica. (p. 318)

\section{SER O NO SER WÉSTERN}

Con respecto al uso de la palabra wéstern para categorizar de un modo u otro a El Topo, es curioso notar que en ninguna parte de su metraje se indica que las acciones se desarrollan en algún territorio del Oeste de los Estados Unidos de América. En ese sentido, y según lo expresado por los autores antes mencionados, ¿qué es lo que hace afirmar a algunos que El Topo es un wéstern? 
La respuesta a esa pregunta la podemos encontrar justamente en el hecho de que $E l$ Topo presenta imágenes características de muchas cintas del género, como los planos generales que devienen en vistas panorámicas de zonas similares al Monument Valley que aparecen en las películas del Oeste de John Ford, o el saloon; y también personajes como el vaquero montado en caballo, interpretado por el propio Alejandro Jodorowsky, y su traje de cuero, oscuro como el del Django del clásico homónimo del spaghetti western del año 1966, o la vaquera que lo persigue en sus enfrentamientos con los cuatro maestros del revólver, con un látigo en mano al estilo del personaje de Barbara Stanwyck en Cuarenta pistolas (Forty Guns, 1957) de Samuel Fuller. Asimismo, El Topo expone algunos temas característicos del wéstern, como el viaje a caballo, la esclavitud y la masacre de poblados. En ese contexto, ¿cómo es que el mítico filme pone en cuestión su calificación como wéstern?

A lo largo del filme, hay una dinámica de afirmación y posterior negación del género. Se introducen las convenciones del wéstern para que a continuación sean contradichas. Por ejemplo, en una secuencia del filme, el Topo, vestido con su oscuro traje de cowboy, pronuncia palabras del Antiguo Testamento para después quitarse su correa de balas y su sombrero, y colocarse en la posición de loto, común en los practicantes del yoga.

Los típicos duelos de los wésterns, que se ganan con balas, en el filme de Jodorowsky más bien se pierden una vez que se mata al oponente, tal como se aprecia en el enfrentamiento con los cuatro maestros del revólver: sea este o un personaje yogui, o un hombre de discurso sufí, o algún poblador músico de reminiscencias alquimistas, o un sujeto de pensamiento taoísta. El enfrentamiento con este último personaje es elocuente en su demostración de cómo la película emplea el wéstern para después negarlo de la forma señalada.

El cuarto maestro del revólver con el que se enfrenta el Topo es un hombre despeinado, de apariencia primitiva (Agustín Isunza), con un paño que cubre su sexo y que apenas posee una red para cazar mariposas, con la cual detiene las balas que le dispara el protagonista. Una de las frases que le dice el maestro al Topo, antes de suicidarse para demostrarle que la vida no le importa, es: “Cómo podías ganar si yo no combato? No tengo nada, aunque hubieras hecho una trampa, no me hubieras podido quitar nada". Una vez que se dispara una bala sobre el pecho, el maestro le dice al Topo "Perdiste".

En cuanto hay un duelo con un hombre vestido de vaquero y armado, se afirma la convención del wéstern; en cuanto el personaje victorioso es el que muere y el derrotado es el que sobrevive, se niega dicha convención. Tal negación está justamente inspirada en el taoísmo, que a través del texto Tao Te Ching de Lao Tse (2008), en su capítulo 46, plantea: “iNo hay mayor aflicción que las pasiones terrenales desenfrenadas! ¡Nada arruina más que el deseo de multiplicar tesoros terrenales! ¡Quien sabe satisfacerse con lo que tiene siempre será feliz!" (p. 27). 
La negación del wéstern consiste justamente en cómo, por un lado, el cuarto maestro del revólver se distancia del duelista cazarrecompensas arquetípico del género, viviendo como alguien que busca alejarse de los tesoros terrenales para ser feliz; $\mathrm{y}$, por otro, en la forma en que su antagonista, movido por la pasión de la victoria, muy característica de las cintas del Oeste, fracasa justamente por esa ambición. En ese sentido, el juego con el wéstern de El Topo se acerca más a la calificación de Diego Moldes de la película como un antiwéstern. Siguiendo las afirmaciones de André Bazin, los mitos en los que se inspira el filme de Jodorowsky no son Buffalo Bill o Sundance Kid, sino Buda o Lao Tse. El filme toma el wéstern para desmitificarlo y convertirlo en algo opuesto, contrario.

En esta línea, Rosenbaum (2018) recuerda que Pauline Kael calificó a El Topo como un acid western en una crítica publicada en la revista The New Yorker, en el año 1971, y que posteriormente cogió dicha expresión para denominar wésterns contraculturales. Por su parte, Hoberman y Rosenbaum (1991, p. 77) cuentan que, con la expansión de la guerra de Vietnam y la mayoría de edad de la generación del baby boom, se impone la contracultura, una amalgama juvenil de políticas radicales, misticismo oriental (u ocultista), libertad sexual, drogas alucinógenas, estilos de vida comunales y rock ' $n$ ' roll, la cual estaba lo suficientemente extendida (e incluso organizada) para verse a sí misma como un movimiento ${ }^{2}$.

Rosenbaum (1996) señala como un primer caso de acid western a la película El tiroteo (The Shooting, 1966) de Monte Hellman, con personajes que deambulan por el desierto como atrapados de manera semejante a los personajes de la obra de teatro Esperando a Godot (En attendant Godot, 1952) de Samuel Beckett, y un final abierto, contado con ralentíes y un montaje que crean un halo lisérgico. El Topo, comprendido como un acid western, comparte con el filme de Hellman ese mismo halo, pero, además, profundiza en su relación con la contracultura mediante el empleo de imágenes o frases de religiones o sistemas filosóficos asiáticos. De esa manera, niega las convenciones más tradicionales del género, y por eso mismo es un antiwéstern.

\section{VOLVER DE LA MONTAÑA, O DEL FUTURO}

La montaña sagrada es un filme dividido en tres partes: en la primera, un hombre de apariencia crística (Horacio Salinas) realiza un camino que lo lleva a un proceso de iniciación espiritual por parte del personaje conocido como el Alquimista (interpretado por el propio Jodorowsky); en la segunda parte, ambos viajan a distintos planetas que

2 El texto original dice así: “As the Vietnam War expanded and America's 'baby-boom' generation came of age, the underground was superseded by the 'counterculture' -a youthful amalgam of radical politics, oriental (or occult) mysticism, 'liberated' sexuality, hallucinogenic drugs, communal life-styles, and rock ' $n$ ' roll that was sufficiently widespread (and even organized) to see itself as a movement'. 
reflejan una serie de males de la sociedad occidental; y en la tercera, el Alquimista y los líderes de aquellos planetas buscan la inmortalidad ascendiendo a una supuesta montaña sagrada.

Johnston (2013) resume las definiciones de la ciencia ficción de H. G. Wells (quien usó al respecto la expresión fantasías de posibilidad), de John Wyndham (según él, el género presupone una tecnología, o un efecto de esta, o una alteración en el orden natural o de la humanidad, que hasta el momento de escribir no se ha experimentado realmente), de Theodore Sturgeon (la ciencia ficción para este autor trata de un problema humano y de una solución humana, que no podría haber ocurrido sin un contexto científico), de Kingsley Amis (el género parte de una hipótesis a partir de innovaciones científicas y tecnológicas, y en conexión con un origen humano o extraterrestre) y de John Campbell Jr. (el género es un esfuerzo para predecir el futuro a base de hechos conocidos). A partir de ellas afirma:

[En] la narrativa de ciencia ficción hay nociones recurrentes de lo que contiene toda la ciencia ficción, independientemente del medio en el que se expresa. Un posible desarrollo futuro dentro de la ciencia o del mundo natural, originado por una fuerza humana o desconocida, que debe ser entendida, controlada o destruida. La tecnología es clave para muchas de esas definiciones, lo que sugiere que la ciencia ficción depende tanto del elemento "ciencia" como de la ficción. (Johnston, 2013, introducción, párrafo 1)

Por eso mismo, el autor asevera que la definición del género desde una perspectiva académica podría centrarse en áreas temáticas alrededor de la tecnología, la ciencia, el futurismo o la figura del otro (Johnston, 2013). Ello abarca otras definiciones de la ciencia ficción recogidas por Urrero (1994, introducción), como la de Jack Williamson ("La ciencia ficción maneja futuros hipotéticos. En otras palabras, podríamos definirla como la exploración imaginativa de las posibilidades científicas") o la de Norman Spinrad (“Todo lo escrito acerca de lo que podría ocurrir, pero no ocurre aún”). Según Pinel (2009), la ciencia ficción:

es un americanismo que yuxtapone dos palabras antagonistas, además de insuficientes para definir un género cinematográfico que se basa en la anticipación. No existe ciencia ficción sin un salto brutal y traumático hacia el futuro. La ciencia ficción crece en los lindes de lo fantástico. El término engloba a películas de temática y estilos muy diversos, que se fundamentan en apariencias científicas para desarrollar su ficción. (p. 68)

Los ocho acompañantes del personaje de imagen crística, quienes comandan cada uno de los planetas, están dotados de una simbología propia del eneagrama de Gurdjieff, explicada ya en detalle por Andrea Chignoli en su libro Zoom back camera! El cine de

$3 \quad$ El texto original dice así: "Within these five different definitions of the science fiction narrative there are recurring notions of what all science fiction contains, regardless of medium. A potential future development within science or the natural world, caused by human or unknown force, which has to be understood, tamed or destroyed. Technology is key to many of these definitions, a suggestion that science fiction is as reliant on the 'science' element as the fiction". 
Alejandro Jodorowsky (2009, p. 57), figura que, además, aparece en la mesa que derriba el Alquimista hacia el final de la cinta. Sin embargo, el viaje que hace el personaje parecido a Jesús se asemeja a los que hacen muchos protagonistas de la ciencia ficción. Las visiones próximas a este género en la película de Jodorowsky son distópicas, giran sobre representaciones maquinales que someten al ser humano: la industria de prótesis de Fon (Juan Ferrara), que cambia radicalmente la fisonomía de sus clientes; el robot erótico y capaz de reproducirse sexualmente en el planeta de Klen (Burt Kleiner); los juguetes que funcionan como cascos en las cabezas de los niños, para que se les inocule un odio hacia los peruanos, en el planeta de Sel (Valerie Jodorowsky); o las armas de colorida estética, flower power, o de formas religiosas (de cruz, de Buda o de menorá) que se utilizan en el planeta Marte, dirigido por Isle (Adriana Page), donde también se usan drogas para generar delirios que llevan a una violencia que se emplea en un contexto de guerra.

En dichos planetas, están las fantasías de posibilidad de H. G. Wells: se luce en el marco de la ficción una tecnología de la belleza, armamentística y erótica, que aún no ha podido ser experimentada en el mundo real, para expresarlo en términos de Wyndham y de Spinrad. Por lo tanto, aquellos viajes del Alquimista y su discípulo son, siguiendo la definición de Jack Williamson, imágenes de futuros hipotéticos o alucinantes exploraciones imaginativas de las posibilidades científicas. La mayor parte de los conceptos utilizados para la denominación de la ciencia ficción se vierten claramente en la segunda parte de La montaña sagrada.

Analizando la película en detalle, se encuentra el tema del viaje a otros planetas, propio de la ciencia ficción, en medio de decorados que en el género, según Pinel (2009), pueden ser cotidianos o futuristas. Para el autor, la figura del robot y el tema del temor a una sociedad tiránica también pertenecen al género (p. 69) y están presentes en $L a$ montaña sagrada. Sin embargo, en la tercera parte de la película, se muestra a los personajes no solo alejándose de la tecnología, sino, además, rechazando el cuerpo que estuvo en contacto con dicha tecnología: queman réplicas de sus cuerpos desnudos, se rapan como monjes budistas al igual que el protagonista de El Topo y, a medida que ascienden hacia la supuesta montaña sagrada en la que alcanzarían la inmortalidad, afirman que van perdiendo la sensación de partes de sus extremidades.

Si a lo largo de El Topo se va afirmando y negando el género del wéstern, la segunda parte de La montaña sagrada está signada por la ciencia ficción, mientras que la tercera niega absolutamente dicho género. Por ello, es importante destacar algunos aspectos religiosos para comprender la relación compleja que tienen ambos filmes con los géneros cinematográficos. Uno de ellos es el término atman, que se comprende en el hinduismo como un alma individual (De la Torre Fernández, 2012, parte I, subtítulo 2, párrafo 16). El otro es el maya, estado que puede describirse en los siguientes términos: 
Una de las escuelas más conocidas [del hinduismo] es el Advaita Vedanta, que concibe al mundo como una ilusión o maya. Para esta, nada existe, todo es ilusión, una especie de sueño del que uno se despierta y entonces descubre que los leones que lo amenazaban en sus pesadillas, en realidad, no existen. (De la Torre Fernández, 2012, parte I, subtítulo 7, párrafo 5)

En La montaña sagrada, una vez que los exlíderes de los planetas llegan a la cima de la montaña en la que alcanzarían la inmortalidad, se encuentran con el Alquimista, y una de las expresiones con las que se dirige el personaje de Jodorowsky a ellos es: “¿Pero esta vida es real? No, es un filme" ("But, this life is reality? No. It is a film"). La expresión autorreferencial del filme, en la voz del Alquimista, apela al acto de vivir una ilusión cinematográfica, de la que se despojan los personajes en un juego metaficcional en el cual el Alquimista rompe la cuarta pared, mira hacia la cámara y dice: “Zoom back camera!". A continuación, acompañado por el equipo de rodaje del propio filme que estamos viendo, señala lo siguiente: “Somos imágenes, sueños, fotografías. ¡No debemos quedarnos aquí! ¡Prisioneros! Tenemos que romper la ilusión. Esto es maya” (“We are images, dreams, photographs. We must not stay here! Prisoners! We shall break the ilussion. This is maya"). Una vez que el Alquimista derriba la mesa con el ya referido eneagrama de Gurdjieff, alrededor del cual se sentó con sus discípulos, se despide: “Adiós a la montaña sagrada. La vida real nos espera" ("Goodbye to the holy mountain. Real life awaits us").

Los personajes, al sustraerse de la ilusión cinematográfica, de sus imágenes, sueños o fotografías, se apartan, como lo dice el propio personaje de Jodorowsky, del maya, del mundo como ilusión. Dicha ilusión debe ser rota, no se debe prolongar. En ese sentido, que La montaña sagrada haya estado compuesta en su narrativa por imágenes o temáticas propias de la ciencia ficción, que desaparecen una vez que los personajes van en búsqueda de la inmortalidad, representa justamente la necesidad final de la película de quebrar el estado ficcional en el que nos ha sumergido para encontrarnos con nuestro atman, nuestro propio ser, nuestra alma. Por ello, al final el Alquimista se despide de la montaña sagrada, del espejismo fílmico, y afirma que la vida real es la que nos espera, que es la del atman, una vida sagrada. Esto último se desprende de lo afirmado en el sloka número 2 del texto sagrado conocido como Mândûkya Upanishad, que dice: "Porque realmente todo lo que existe es Brahman. Y este Ser interno (atman) es Brahman" (traducido por Albrecht, 2003, p. 15). Según el Atharva Veda, un tipo de conocimiento o sabiduría propio del hinduismo, el Brahman es el Ser Supremo, y "atman y Brahman son lo mismo" (De la Torre Fernández, 2012, parte I, subtítulo 2, párrafo 16). Al despertar del maya, uno descubre que es parte de la totalidad divina. Dicho Ser Supremo es el todo en el que realmente vivimos.

Así pues, los cuerpos de los personajes son parte de ese estado de ilusión, del maya que se deja atrás. Por ello, se revela que los cuerpos del Alquimista y sus seguidores

4 Forma de verso hinduista. 
son una mera presencia de la ilusión cinematográfica, que tomó por algunas decenas de minutos el género de la ciencia ficción. Una situación semejante identificamos en El Topo. Larouche (1985) destaca que cualquier wéstern generalmente se reduce a tres estructuras narrativas, las cuales de un modo u otro están integradas en el filme en cuestión, a diferencia de películas que optan por una u otra (p. 46):

1. El cumplimiento de una promesa o compromiso por parte del héroe hacia el grupo al que pertenece. El protagonista se ve obligado a proteger o a una comunidad, o a una mujer en peligro, o a vengar una muerte que quedó impune.

2. El tema de la búsqueda, que puede dirigirse hacia un tesoro, a través de obstáculos reflejados en personajes enemigos o traidores. Puede ocurrir que en este caso no se logre el objetivo, pero al final se manifiesta una ganancia moral que consagra al héroe.

3. La resolución de enemistades o antagonismos a favor de valores como la solidaridad humana. Grupos tradicionalmente opuestos (por ejemplo, indios y blancos) dejan de lado la lucha. El odio queda atrás y se restaura la libertad y el orden.

En el caso de estas estructuras narrativas, que en efecto están insertadas en la película de Jodorowsky, encontramos nuevamente esa dinámica antes descrita de afirmación del género y subsecuente negación. El personaje del Topo tiene la promesa de liberar a los freaks de la cueva en la que están presos, pero después, una vez liberados, mueren baleados en la ciudad. Justamente, la liberación consistía en la posibilidad de que coexistieran solidariamente dichos seres mutilados o tullidos con quienes ya habitaban la ciudad, signada bajo aquel símbolo del triángulo y el ojo que aparece en los billetes de dólar. Aparentemente, el tema de la búsqueda se manifiesta en cuanto a que si bien el Topo no logra los objetivos descritos líneas atrás, hay una ganancia moral en cuanto ejecuta un castigo de aura apocalíptica sobre los habitantes de la ciudad, por haber asesinado a los inocentes fenómenos.

Sin embargo, el Topo no es el héroe desaparecido al que se recuerda como ser noble, tal como sucede con el personaje de John Wayne en un wéstern revisionista crepuscular como El hombre que mató a Liberty Valance (The Man Who Shot Liberty Valance, 1962) de John Ford, cinta en la que es apreciado por el personaje de James Stewart como un héroe secreto, que no recibió el reconocimiento debido. El personaje de Jodorowsky no muere después de haber realizado un acto heroico: él mismo decide quitarse la vida, como un bonzo, encendiendo el querosene que se ha rociado sobre el cuerpo. Por ello, hay que recordar que en los wésterns canónicos apreciamos la obtención de un objeto de valor por parte de un sujeto narrativo principal, sea la sobrina rescatada por el personaje de John Wayne al final de Más corazón que odio (The Searchers, 1956) de John Ford, o el dinero 
ganado después de un duelo por el personaje de Clint Eastwood en la última escena de El bueno, el feo y el malo (Il buono, il brutto, il cattivo, 1966) de Sergio Leone ${ }^{5}$.

El caso de la ciencia ficción es más complejo en cuanto al aspecto narrativo. Es común hallar un esquema narrativo de búsqueda (Greimas, citado por Fontanille, 2001, p. 100) en ese género cinematográfico, desde Freder (Gustav Fröhlich), que consigue como objeto de valor un acuerdo de paz después de vencer al científico Rotwang y su androide de la falsa María en Metrópolis (1927) de Fritz Lang, hasta Montag (Oskar Werner), que se enfrenta a una sociedad que le ordena quemar libros y logra atesorar uno de ellos, justamente como un preciadísimo objeto de valor, aprendiéndolo de memoria, para unirse así a una comunidad de "hombres libro" como él en Fahrenheit 451 (1966) de François Truffaut. Sin embargo, algunas cintas de ciencia ficción de fines de los sesenta e inicios de los años setenta, como 2001: Una odisea del espacio (2001: A Space Odyssey, 1968) de Stanley Kubrick o Solaris (Solyaris, 1972) de Andréi Tarkovski, alteran el sentido del tiempo, apelan a finales abiertos o confunden estados que pueden ser de vigilia y de sueño, en la línea del cine de la modernidad.

Por eso, la manera en que se califica a una película de ciencia ficción, a diferencia del wéstern, descansa en sus imágenes y sus temas. Pero, a pesar de ello, La montaña sagrada, con el viaje de sus personajes en búsqueda de inmortalidad en la parte tercera y final del filme, remueve cualquier imagen o tema de naturaleza futurista. Vemos a los discípulos del Alquimista actuando igual que el Topo, separándose de una serie de objetos de valor emblemáticos del género, sean los robots eróticos, la tecnología para inocular el odio hacia los peruanos en el cerebro de los niños, o la empleada para implantar prótesis que embellecen cualquier parte del cuerpo.

En ese sentido, el cuerpo aparece como un medio de alteración de los géneros tomados por El Topo y La montaña sagrada. Los personajes principales de ambas películas poseen un cuerpo al que tratan como un objeto que se ha de dejar de lado: sea el cuerpo humano en El Topo, sea el cuerpo tecnológico y cinematográfico en La montaña sagrada. Trascender esos cuerpos abiertamente insertados en imágenes y temas propios de géneros cinematográficos vincula a los sujetos narrativos a otro acto: aquella renuncia que el budismo define como nekkhamma, que implica eliminar todo lo que nos sujeta a los placeres de los sentidos (Buswell Jr. y López Jr., 2014). Ambos personajes renuncian a placeres o deseos que han sido característicos de los cuerpos que han poseído: al placer de matar en El Topo, o a la ambición por la inmortalidad en La montaña sagrada.

5 A diferencia de los wésterns crepusculares, en los que vemos a los vaqueros viviendo sus últimos momentos, como el John Wayne de El hombre que mató a Liberty Valance o el Butch de La pandilla salvaje, películas en las que la muerte es convertida en mito o acto de melancolía, pero que se alejan del sentido de la muerte como vía para alcanzar una plenitud espiritual, tal como lo expresa el filme de Jodorowsky. 
Desviar la orientación que el cuerpo suele tener en el wéstern o la ciencia ficción es el recurso empleado por Alejandro Jodorowsky para trascenderlos y crear una obra única y original. Usa los géneros para, finalmente, escapar de las clasificaciones más rígidas. Es en este aspecto que hallamos la riqueza de su condición de autor cinematográfico.

\section{REFERENCIAS}

Albrecht, A. (Trad.). (2003). El Mândûkya Upanishad. Buenos Aires: Editorial Hastinapura.

Buswell Jr., R. E., y López Jr., D. S. (2014). The Princeton dictionary of Buddhism. Princeton, NJ: Princeton University Press, edición Kindle.

Casas, Q. (1994). El wéstern, el género americano. Barcelona: Paidós.

Chignoli, A. (2009). Zoom back camera! El cine de Alejandro Jodorowsky. Santiago de Chile: Uqbar.

De la Torre Fernández, A. (2012). Entre Maestros, Dioses y Demonios. Una introducción al pensamiento de la India. Bloomington, IN: Palibrio.

Fontanille, J. (2001). Semiótica del discurso. Lima: Universidad de Lima, Fondo Editorial.

Hall, M. K. (2001). Now you are a killer of white men: Jim Jarmusch's Dead Man and traditions of revisionism in the western. Journal of Film and Video, 52(4), 3-14.

Hoberman J., y Rosenbaum, J. (1991). Midnight movies. Nueva York, NY: Da Capo Press.

Johnston, K. M. (2013). Science fiction film. A critical introduction. Oxford, NY: Berg.

Lao Tse. (2008). Tao Te Ching. Bancroft: Lulu.

Larouche, M. (1985). Alexandro Jodorowsky. Cinéaste panique. Montreal: Presses de l'Université de Montréal; Éditions Albatros.

Moldes, D. (2012). Alejandro Jodorowsky. Madrid: Cátedra.

Monteleone, M. (1993). La talpa e la fenice. Il cinema di Alejandro Jodorowsky. Bolonia: Granata Press.

Pinel, V. (2009). Los géneros cinematográficos. Géneros, escuelas, movimientos y corrientes en el cine. Barcelona: Ma Non Troppo.

Rosenbaum, J. (28 de noviembre de 1996). Acid Western. Recuperado de https://www. jonathanrosenbaum.net/1996/06/acid-western/

Rosenbaum, J. (27 de noviembre del 2018). Responding to some questions about "Acid Westerns" and Dead Man. Recuperado de https://www.jonathanrosen baum.net/2018/11/responding-to-some-questions-about-acid-westerns-anddead-man/

Urrero, G. (1994). El cine de ciencia ficción. Barcelona: Royal Books. 